\title{
Malaria Perceptions among Medicine Vendors in Buea Community: An Assessment of Knowledge of Malaria and Conditions of Antimalarial Drug Dispensing
}

\author{
Marcelus U. Ajonina ${ }^{1,4}$; Kenric B. Ware ${ }^{3}$; Deodata B. Ngonga ${ }^{2}$; Raphael A. Abong ${ }^{1,4}$; Carine K Nfor ; Tobias O. Apinjoh \\ ${ }^{1}$ School of Health Sciences, Meridian Global University, Buea, Southwest Region, Cameroon \\ ${ }^{2}$ School of Health and Human Services, Saint Monica University, Buea, Southwest Region, Cameroon \\ ${ }^{3}$ South University School of Pharmacy, Columbia, SC 29203, USA \\ ${ }^{4}$ Meridian Global Education and Research Foundation, Buea, Southwest Region, Cameroon \\ ${ }^{5}$ Department of Biochemistry and Molecular Biology, University of Buea, Cameroon
}

\begin{abstract}
Background: Lack of knowledge of rational use of antimalarial drugs among medicine vendors is a serious problem, notably in areas of intense transmission. These misunderstandings increase the risks of resistance and adverse drug reactions. This study aimed to assess knowledge of malaria and environments wherein medicine vendors dispense antimalarials in the Buea community.

Methods: Administration of a community-based cross-sectional survey of a random sample of 140 medicine vendors living within the Buea community occurred between March and June 2017. The survey sought to obtain information from medicine vendors on their general knowledge of malaria as well as their dispensing practices. Statistically significant findings were associated with $p \leq .05$.

Results: The majority of participants were aware that use of insecticide - treated bed nets (ITNs) and maintenance of a clean environment equate to effective malaria prevention efforts. Alternatively, only one-third of participants correctly attributed the causative organism of malaria to being protozoan. Participants employed within drugstore settings had less knowledge of malaria than their hospital/community counterparts did. A directly proportional relationship existed between the amount of experience that participants had in their respective disciplines with an increased knowledge of malaria overall.

Conclusion: These findings reveal fluctuating knowledge of malaria among study participants. Reported antimalarial dispensing practices also warrants room for improvement. Routine monitoring and evaluation to prevent emergence of resistant strains to current efficacious antimalarials remains paramount.
\end{abstract}

Keywords: antimalarials, drug retail outlets, dispensing, drug resistance, prescription

\section{Background}

Malaria remains a leading cause of morbidity and mortality worldwide. The global malaria burden is disproportionately high in Sub-Saharan Africa, which accounts for $90 \%$ of malaria cases and $92 \%$ of malaria deaths, mostly in children under five years of age. ${ }^{1}$ In Cameroon, over $90 \%$ of the population is at risk of malaria infection and approximately $41 \%$ have at least one episode of the disease each year. ${ }^{2}$ Moreover, malaria accounts for $50-56 \%$ of morbidity and $40 \%$ of the annual mortality in children less than five-years old. ${ }^{3}$ Malaria also imposes a heavy economic burden on both individuals and governments, with an estimated direct cost of at least US $\$ 12$ billion per year. ${ }^{1}$

Significant progress in malaria control has been recorded globally that has resulted in a global decrease in malaria incidence and death rate by $21 \%$ and $29 \%$ between 2010 and 2015, respectively, in all age groups. An estimated 6.8 million malaria deaths have been avoided globally since $2001 .{ }^{1}$ Nevertheless, the emergence and spread of resistance to antimalarial drugs and insecticides,

Corresponding author: Marcelus U. Ajonina, PhD

School of Health Sciences, Meridian Global University and Meridian Global Education and Research Foundation, Buea, Southwest Region, Cameroon; Email: majonin@gmail.com coupled with the lack of a vaccine, have been an impediment to the management of malaria especially in endemic regions. ${ }^{1}$ Resistance strains have emerged nearly to all available antimalarials. ${ }^{1,4}$ The effectiveness of these antimalarials has increasingly waned including examples such as chloroquine (CQ), a mainstay of 20th century malaria eradication efforts, ${ }^{4}$ sulfadoxine-pyrimethamine (SP), an alternative available for large scale implementation for the treatment of uncomplicated malaria, ${ }^{1}$ and atemisinin-based combination therapy (ACT), a current first-line treatment for uncomplicated malaria. ${ }^{1}$ Resistance is also known to affect all major malaria vector species and all four recommended classes of insecticides. Since 2010, a total of 60 countries have reported resistance to at least one class of insecticide, with a total of 49 of those countries reporting resistance to two or more classes. ${ }^{5}$

This evolution of malaria parasite drug resistance highlights the need to identify and constantly monitor strategies that could extend the therapeutic use of antimalarial drugs. Additionally, there is the need to ascertain and ensure that rational control policies, once adopted, are properly implemented.

Current strategies for managing antimalarial resistance focus on four key elements which include: preventing the emergence of antimalarial drug resistance through rational prescribing and 
dispensing of antimalarials; ${ }^{4,5}$ routine monitoring of therapeutic efficacy of first-line and second-line ACTs to detect early changes in P. falciparum susceptibility to antimalarial drugs in endemic countries using in vivo efficacy assays and molecular markers; ${ }^{5}$ ensuring a continuous pipeline of new antimalarial medicines with a paradigm shift towards complementary and alternative medicine (medicinal plants); and containing the spread of antimalarial drug resistance once it has emerged. ${ }^{6}$ Therefore, strategies to elicit feedback from citizens residing in areas impacted by malaria, along with those directly involved in the dispensing of antimalarials seem prudent. Particularly, a heightened focus on perceptions of malaria's etiology, methods of acquisition and mechanisms for its prevention, in addition to antimalarial prescribing parameters, is apt to inform prevailing rationales for rapid spread of resistant strains especially in endemic regions. ${ }^{7}$

Antimalarial drug resistance emerges due primarily to patient and health system noncompliance to practices regarding malaria treatment policy including irrational prescribing and dispensing of antimalarials, misdiagnosis, incorrect dosing, non-adherence to antimalarial treatment and poor drug quality. ${ }^{7-10}$ The above phenomena have increasingly been observed among medicine vendors. Several studies have reported high proportions of presumptive treatment for malaria especially in unauthorized medicine vendors. ${ }^{11}$ These tendencies have the potential to facilitate resistance by greatly increasing the number of people who are treated unnecessarily but will still be exerting selective pressure on the circulating parasite population. ${ }^{11,12}$

It has further been reported that some medicine vendors lack knowledge of prescribing restrictions applied to antimalarial medicines. ${ }^{13}$ This study aimed to assess medicine vendors in the Buea health district knowledge of etiology, transmission, clinical presentations, and prevention of malaria, in conjunction with their understanding of conditions for antimalarial drug dispensing in Cameroon.

\section{Methodology}

This study was conducted in the Buea Health District (BHD) in the South West Region of Cameroon. BHD has an estimated human population of 147,842 inhabitants distributed over 67 communities. ${ }^{10}$ Indigenes of the district are of the Bakweri tribe and part of the Bantu ethnic group. ${ }^{14}$ Buea has a Cameroon- type equatorial climate characterized by fairly constant temperatures ranging from $18^{\circ} \mathrm{C}-29^{\circ} \mathrm{C}$ with average humidity of $80 \%$ and two seasons: a short dry season (November-March) and a long rainy season (March-November). Malaria transmission occurs all year round with two peak periods, the first in April and May and the second in October and November. ${ }^{15}$ The prevalence of malaria parasitaemia in the low-altitude areas ranges from $30 \%$ in the dry season to $84 \%$ in the rainy season. ${ }^{16} \mathrm{P}$. falciparum is the main species accounting for up to $96 \%$ of malaria infections in the area while Anopheles gambiae is dominant (most aggressive and most active of the three malaria vectors An. gambiae, An. funestus and Anopheles nili), accounting for up to 72.7\% of transmission infection rates. ${ }^{17}$ Entomological Inoculation Rate (EIR) to An. gambiae are as high as 287 infective bites/ person/year and 3.93 infective bites/person/night. ${ }^{18}$ The study conducted from March to June 2017 was a communitybased cross-sectional survey of medicine vendors who reportedly have been selling medications in the health area for at least two years. The sample size was calculated using a standard formula for prevalence studies. ${ }^{19}$

$$
n=\frac{z \alpha^{2} p q}{d^{2}}
$$

Where $\mathrm{n}=$ sample size, $\mathrm{Z} \alpha=$ standard normal deviate, set at 1.96 (for $95 \% \mathrm{Cl}$ ), $\mathrm{p}=$ the estimate of target population who dispense medication in the district (10\%) and at $95 \%$ confidence interval and $d$ is a $5 \%$ relative precision. A $10 \%$ adjustment for nonresponses and invalid responses was added.

Prior to data collection, a semi-structured questionnaire was developed and pre-tested for validity. The questionnaire was designed to obtain information from medicine vendors on knowledge of malaria prevention and acquisition along with prescriptive authorities for dispensing antimalarial medications. The first part of the questionnaire contained demographics including gender, age (in years), professional qualifications, dispensary type, and experience (in years). The second part was structured to capture information regarding knowledge about malaria etiology, transmission, signs and symptoms and prevention. For this component of the questionnaire, a "Select All that Apply" format was employed. Practices regarding dispensing of antimalarial medications were assessed using questions about conditions for antimalarials dispensing and knowledge of who is qualified to prescribe antimalarial medications. In addition to the researcher, two research assistants were recruited and trained to administer the structured questionnaire.

The research assistants were trained on the tools to be used, purpose of the study and how to approach respondents and obtain consent. Data were collected by face-to-face interviews, with respondents required to meet the qualification of dispensing antimalarial medications for at least two years. Prior to data collection, the purpose of the study was carefully explained to respondents and written informed consent was obtained before questionnaire administration.

Data were double entered in Microsoft Excel and analyzed using SPSS Statistics 20.0 (IBM Corp, Atlanta, GA, USA). Descriptive statistics were carried out to measure percentages, averages, and relative frequencies of the variables. Relationships among the dependent variable, knowledge of malaria, and independent variables, gender, age group (in years), professional qualifications, dispensary type, and experience (in years), were assessed using the Pearson's Chi-Squared ( $\mathrm{x} 2$ ) test at $95 \% \mathrm{Cl}$. Statistical level of significance was set at $p \leq .05$. Ethical approval was obtained from the Institutional Review Board of Saint Monica University (No.2017/SMU/IRB/36). Administrative authorizations 
were sought from the South West Regional Delegation of Public Health and the Buea District Health Service (R11/MINSANTE/SWR/RDPH/PS/40/709). Only individuals who volunteered to participate by signing a written informed consent, after adequate sensitization were enrolled.

\section{Results}

One hundred and forty respondents aged $17-50$ years old participated in the study. Table 1 displays the characteristics of the sample. Of note, this cohort contained more than twice as many males than females. The predominate age group featured participants greater than 20 years but less than 30 years old. Professional designations that were in the majority were equally split between those with nursing credentials and participants without a professional diploma. Respondents that were mostly in a drugstore setting, with less than one-half of a decade of professional experience, outnumbered study counterparts in other dispensary types, and with greater years of experience, in an almost two-to-one fashion, respectively.

Table 2 displays knowledge of respondents' awareness of causes, transmission, signs and symptoms, along with prevention strategies of malaria. Mosquitoes were implicated in some capacity by the majority of respondents as being both causative agents and transmission considerations for malaria; the former assertion dubbed as inaccurate, as protozoan was the correct reply; the latter consideration as partially correct, as the desired response was mosquito bite or blood transfusion. Respondents were largely familiar with signs and symptoms in isolation that may constitute malarial diagnoses such as fever, body weakness, vomiting, and headache. However, participants were less likely to select at least three signs and symptoms collectively. A similar trend existed with knowledge of prevention techniques, with more responses garnered for insecticide-treated-bed nets (ITNs) and clean environments individually than their synergistic effects.

Table 3 displays participant demographics with correct knowledge of malaria based upon domains depicted in Table 2. Two of the participant demographics reported to have the highest representation in Table 1 (male and age 20-29) demonstrated the greatest overall knowledge of malarial principles. However, the remaining demographic types, professional qualification, dispensary type, and years of experience yielded percentages of correct knowledge that did not necessarily mirror the majority number of respondents. Specifically, statistically significant differences in percentages of correct knowledge occurred within both professional qualification and years of experience categories $(p<.005)$.

Table 4 displays participant feedback regarding conditions for antimalarial drug dispensing. The percentage of respondents identified as having a hospital/community pharmacy designation conveyed a higher level of understanding of the necessity of a prescription for anti-malarial medications by physicians, pharmacists, and nurses than drugstore participants. The hospital/community pharmacy contingent was also less likely to believe that any health worker or any person could perform antimalarial dispensing in general. These findings translated into a statistically significant difference in good overall dispensing practices between the hospital/community pharmacy and drugstore sectors $(p=.02)$.

Respondent's overall knowledge of malaria was deduced from the correct responses provided for the various aspects of malaria (causative agent, mode of transmission, signs and symptoms and methods of prevention) presented on Table 2. A participant with correct responses for at least three, two, or one of the aspects was considered to have an excellent, fair and poor overall knowledge, respectively. Majority [55(39.3\%)] of respondents had excellent, while $46(32.9 \%)$ and $39(27.9 \%)$ had fair and poor overall knowledge of malaria, respectively. Furthermore, participants with excellent and fair knowledge were classified as having an appropriate knowledge of malaria overall. In all, 101(72.1\%) of respondents had a good knowledge of malaria while $39(27.9 \%)$ had poor knowledge.

\section{Discussion}

Global malaria eradication is threatened on an unprecedented scale by rapidly growing resistance of $P$. falciparum to conventional antimalarial drugs. A contributing factor to this phenomenon is the misuse of these drugs especially in endemic regions. Overuse of these medications coupled with patient noncompliance to treatment can lead to misdiagnoses, inadequate dosing, incomplete courses and indiscriminate drug use as contributing factors to resistance. ${ }^{9,20}$ This study showed that $>50 \%$ of the drug dispensers in Buea Health District were quite knowledgeable about malaria signs and symptoms as well as preventive methods (Table 2). These findings are aligned with other studies in the district ${ }^{10,21}$ and other endemic regions such as Southeast Iran, Malaysia and South Africa ${ }^{22,23}$ where participants typically have adequate knowledge of the disease owing to their frequent exposure to malaria. The study also revealed poor knowledge on the cause of malaria with majority (62.1\%) of respondents attributing the cause of malaria to mosquitoes (Table 2).

Only $33.6 \%$ knew that a protozoan was the causative agent of malaria. It is plausible that respondents may have been unclear about the distinction between cause and transmission.

Although the population of participants with accurate knowledge about the cause of malaria reported here is relatively high compared to studies in Cameroon (31.5\%), Ethiopia (1.6\%) and Tanzania $(6 \%),{ }^{10,24}$ the limited knowledge may be attributed to the fact that control measures emphasize mosquito related problems rather than the parasite. The study also demonstrates that the knowledge of malaria was strongly associated with level of education. This can be explained by the fact that majority of those who have attained at least secondary level of education with professional diplomas might have been taught about malaria in schools and may also be more likely to read and comprehend information on malaria in print media, radio or 
television. Education clearly influences knowledge about modes of malaria transmission, with educated communities having access to multiple sources of information when compared with their less educated counterparts. ${ }^{21,25,26}$ Special strategies such as community educators are therefore required to reach out to the under educated members of the study area with information, education and communication messages on malaria control measures such as ITN use, care and maintenance of ITN life span for protection against malaria. ${ }^{26}$

With the exception of professional qualification and years of experience, correct knowledge of malaria among participant demographics was similar (Table 3). As it relates to professional qualifications, the category encompassing "Pharmacist/MD/Pharmacy Assistant" demonstrated completely correct knowledge (100\%), being statistically significantly different from the other categories $(p<.005)$.

However, with the multiple professional designations housed within this category, it is difficult to pinpoint the prevailing contributor to these statistically significant findings. The low yield of Pharmacist/MD/Pharmacy Assistant participants $(n=8)$ further complicates the interpretation of these results in relationship to the other groups with almost two to five times greater representation, but less knowledge proficiency. There was a statistically significantly higher level of knowledge observed in the portion of the sample with greater than ten years of experience ( $p$ $<.005)$.

This increased knowledge base in comparison to peer participants appears to be directly proportional to the expertise acquired over time in managing various types of malaria presentations.

In general, both medicine vendors in the hospital/community and drugstore arenas shared consistent beliefs about conditions for antimalarial drug dispensing (Table 4). Some of the uniformity in responses may relate to inconsistent viewpoints on phrases such as "health worker" or "anybody." In light of these possible varying interpretations, coupled with the dichotomous nature of the questions, an ability to confidently confirm or deny appropriate antimalarial dispensing conditions may have been challenging. It is plausible that the hospital/community dispensing settings encountered more patients treated for complex malaria cases than the drugstore-dispensing environment. This would foreseeably necessitate that the hospital/community group of participants remain more in-tuned with clinical developments. Therefore, the statistically significant difference in good overall dispensing practices may have resulted from disparities in the number and nature of encounters with malaria between the two groups $(p=.02)$.

There were some noted limitations to our study. Some answer choices to questionnaire items populated in a co-formulated fashion, e.g., hospital/community pharmacy. These depictions limited abilities to confidently associate respondents' selections with their specific intended descriptions.
Moreover, some respondents may have maintained employment in the hospital/community pharmacy and drugstore settings concurrently. While this disposition may have been in the minority, respondents' categorizations along these lines may have been arbitrary.

Terminology such as "Pharmacy Assistant" may not resonate in other pharmacy settings throughout the world. As a result, any information inferred about this subset of the study sample may be of minimal value globally. Differentiation within the nursing continuum, e.g., licensed practical nurse (LPN) or registered nurse (RN) did not occur. This lack of specification may not allow the respective findings to translate as well to the different members of the nursing profession reviewing these results.

Additionally, clarifying dialogues that ostensibly resulted between the research assistants and the study participants could have confounded the findings.

As the research assistants received training on how to approach respondents, questions directed towards them may have led to certain respondents receiving insights unavailable to others. Nonetheless, this research study overall provided vital information about perceptions of medicine vendors' mindsets towards malaria acquisition, prevention, and antimalarial prescribing constraints. The results generated here are prone to assist public health initiatives continue to address accounts of morbidity and mortality attributed to malaria worldwide.

\section{Conclusion}

Efforts to elevate awareness about malaria prevention, acquisition, and containment remain in high demand. Effectiveness of antimalarial medications are prone to abate if resistance continues to mount. Customizable community messages to target audiences that inspire a sense of responsibility to become and remain informed about malaria control procedures are paramount. The findings reported here indicate that sustained global progress in this regard is well within reach.

\section{References}

1. Center for Disease and Control. Impact of malaria. https://www.cdc.gov/malaria/malaria_worldwide/impact. html. Accessed July 8, 2018.

2. Mbenda HG, Awasthi G, Singh PK, Gouado I, Das A. Does malaria epidemiology project Cameroon as 'Africa in miniature'? J Biosci Med 2014;39(4):727-38.

3. Cameroon National Malaria Control Program, Annual Report 2008. World Health Organization. www.who.int/malaria/publications/countryprofiles/mal2008-cameroon-en.pdf . Accessed July 8, 2018.

4. Attaran A, Barnes KI, Curtis C, d'Alessandro U, Fanello Cl, Galinski MR, Kokwaro G, Looareesuwan S, Makanga M, Mutabingwa TK, Talisuna A, Trape JF, Watkins WM. WHO, the global fund, and medical malpractice in malaria treatment. Lancet 2004;363(9404):237 -240. 
5. World Health Organization. Emergency response to artemisinin resistance in the Greater Mekong subregion. Regional framework for action 2013-2015. http://www.who.int/malaria/publications/atoz/978924150 5321/en/. Accessed July 8, 2018.

6. Lubell Y, Dondorp A, Guérin PJ, Drake T, Meek S, Ashley E, Day NP, White NJ, White LJ. Artemisinin resistance modelling the potential human and economic costs. Malar J 2014;13(452).

7. Banek K, Lalani M, Staedke SG, Chandramohan D. Adherence to artemisinin-based combination therapy for the treatment of malaria: a systematic review of the evidence. Malar J 2014;13(7).

8. Bloland PB. Drug resistance in malaria. Published 2001. www.who.int/csr/resources/publications/drugresist/malari a.pdf . Accessed July 8, 2018.

9. Chipwaza B, Mugasa JP, Mayumana I, Amuri M, Makungu C, Gwakisa PS. Self-medication with antimalarials is a common practice in rural communities of Kilosa district in Tanzania despite the reported decline of malaria. Malar J 2014;13(252).

10. Ajonina MU, Apinjoh TO, Atanga SN, Ayim M, Akomoneh $E A$, Ajonina C. Practices regarding the use of antimalarial medications among inhabitants of the Buea health district, southwestern Cameroon: implications towards malaria treatment policy. JHMN 2015;21:86-95.

11. Uzochukwu BS, Ezeoke OP, Emma-Ukaegbu U, Onwujekwe OE, Sibeudu FT. Malaria treatment services in Nigeria: a review. Niger Med J 2010;51(3):114 - 119.

12. Whitty CJ, Rowland M, Sanderson F, Mutabingwa TK. Malaria. BMJ 2002;325(7374):1221-1224.

13. Kamuhabwa AAR, Silumbe R. Knowledge among drug dispensers and antimalarial drug prescribing practices in public health facilities in Dar es Salaam. Drug Healthc Patient Saf 2013;5:181 - 189.

14. Communes Et Villes Unies Du Cameroun (CVUC). Buea. Published 2014.

http://cvuc.cm/national/index.php/fr/cartecommunale/region-du-sud/142-association/carteadministrative/sud-ouest/fako/404-buea. Accessed July 8 , 2018.

15. Apinjoh TO, Anchang-Kimbi JK, Ajonina MU, Njonguo ET, Njua-Yafi C, Ngwai AN, Mugri RN, Achidi EA. In vivo efficacy of artesunate/sulphadoxine-pyrimethamine versus artesunate/amodiaquine in the treatment of uncomplicated P. falciparium malaria in children around the slope of mount Cameroon: a randomized controlled trial. Biomedicines 2016;4(1):5.

16. Achid EA, Apinoh TO, Achang-Kimbi JK, Mugri RN, Ngwai $\mathrm{AN}$, Yafi CN. Severe and uncomplicated falciparum malaria in children from three regions and three ethnic groups in Cameroon: prospective study. Malaria J 2012;11(215).
17. Wanji S, Tanke T, Atanga SN, Ajonina C, Nicolas T, Fontenille D. (2003). Anopheles species of the Mount Cameroon region: biting habit, feeding behavior and entomological inoculation rates. Trop Med Int Health 2003;8(7):643 - 649.

18. Bigoga JD, Manga L, Titanji VPK, Coetzee M, Leke RGF. Malaria vectors and transmission dynamics in coastal southwestern Cameroon. Malar J. 2007;6(5).

19. Naing L, Winn T, Rusli BN: Practical issues in calculating the sample size for prevalencestudies.

Arch Orofac Sci 2006;(1):9-14

20. Awad AI, Ball DE, Eltayeb IB. Improving rational drug use in Africa: the example of Sudan. East Mediterr Health J 2007;13(5):1202 - 1211.

21. Kimbi HK, Nkesa SB, Ndamukong-Nyanga JL, Sumbele IUN, Atashili J, Atanga MBS. Knowledge \& perceptions towards malaria prevention among vulnerable groups in the Buea Health District, Cameroon. BMC Public Health 2014;14(883).

22. Mazigo HD, Obasy E, Mauka W, Manyiri P, Zinga M, Kweka EJ, Mnyone LL, Heukelbach, J. Knowledge, attitudes, and practices about malaria and its control in rural northwest Tanzania. Malar Res Treat 2010;2010(794261).

23. Aborah S, Akweongo P, Adjuik M, Atinga RA, Welaga P, Adongo PB. (2013). The use of non- prescribed antimalarial drugs for the treatment of malaria in the Bolgatanga municipality, northern Ghana. Malar J 2013;12(266).

24. Aderaw Z, Gedefaw M. Knowledge, attitude, and practice of the community towards Malaria Prevention and control options in anti-malaria association intervention zones of Amahara national regional state, Ethiopia. J Trop Dis 2013;1(3).

25. Erhun WO, Agbani EO, Adesanya SO. Malaria prevention: knowledge, attitude and practice in A Southwestern Nigerian community. Afr J Biomed Res 2005;8(1):25 - 29.

26. Uneke CJ. Impact of placental Plasmodium falciparum malaria on pregnancy and perinatal outcome in subSaharan Africa. Yale J Biol Med 2008;81(1):1 - 7. 
Table 1

Demographics of respondents $(N=140)$

\begin{tabular}{|c|c|c|c|}
\hline \multicolumn{2}{|l|}{ Demographics } & \multirow{2}{*}{$\begin{array}{c}\text { Number (n) } \\
95 \\
\end{array}$} & \multirow{2}{*}{$\begin{array}{c}\text { Percent (\%) } \\
67.9\end{array}$} \\
\hline Gender & Male & & \\
\hline & Female & 45 & 32.1 \\
\hline \multirow{4}{*}{$\begin{array}{l}\text { Age Group } \\
\text { (years) }\end{array}$} & $<20$ & 6 & 4.3 \\
\hline & $20-29$ & 64 & 45.7 \\
\hline & $30-39$ & 56 & 40 \\
\hline & $40-49$ & 14 & 10 \\
\hline \multirow{4}{*}{$\begin{array}{l}\text { Professional } \\
\text { Qualification }\end{array}$} & Pharmacist/MD/Pharmacy Assistant ${ }^{\dagger}$ & 8 & 5.7 \\
\hline & Nurse & 55 & 39.3 \\
\hline & Other Degrees & 22 & 15.7 \\
\hline & No Professional Diploma & 55 & 39.3 \\
\hline \multirow{2}{*}{$\begin{array}{l}\text { Dispensary } \\
\text { Type }\end{array}$} & Hospital/Community Pharmacy $\ddagger$ & 59 & 42.1 \\
\hline & Drugstore & 81 & 57.9 \\
\hline \multirow{3}{*}{$\begin{array}{l}\text { Experience } \\
\text { (years) }\end{array}$} & $<5$ & 87 & 62.1 \\
\hline & $6-10$ & 30 & 21.4 \\
\hline & $>10$ & 23 & 16.4 \\
\hline
\end{tabular}

${ }^{\dagger}$ Pharmacist Assistant: Individual that contributes to the overall medication dispensing process in the presence or absence of formalized educational training.

${ }^{\dagger} \mathrm{MD}$ : Medical Doctor

${ }^{\ddagger}$ Hospital Pharmacy: A pharmacy location that dispenses traditional medications within an inpatient setting.

${ }^{\ddagger}$ Community Pharmacy: A pharmacy location that dispenses traditional medications within a residential clinic facility.

${ }^{\ddagger}$ Drugstore: A medicinal market that encompasses sell of traditional and nontraditional medications and holistic remedies. 
Table 2

Respondents' knowledge of malaria cause, transmission, signs/symptom and prevention $(\mathrm{N}=140)^{\dagger}$

\begin{tabular}{|c|c|c|c|}
\hline \multicolumn{2}{|c|}{ Knowledge Factors } & \multirow{2}{*}{$\begin{array}{c}\text { Frequency } \\
7\end{array}$} & \multirow{2}{*}{$\frac{\text { \% Frequency }}{5}$} \\
\hline & Virus & & \\
\hline & Protozoan & 47 & 33.6 \\
\hline & Bacteria & 9 & 6.4 \\
\hline \multirow[t]{5}{*}{ Causative agent } & Mosquito & 87 & 62.1 \\
\hline & Mosquito bite & 135 & 96.4 \\
\hline & Dirty water & 18 & 12.9 \\
\hline & Contact with patient & 4 & 29 \\
\hline & Blood transfusion & 8 & 5.7 \\
\hline \multirow[t]{7}{*}{ Transmission } & $\begin{array}{l}\text { Mosquito bite or blood } \\
\text { transfusion }\end{array}$ & 143 & $>100 \%$ \\
\hline & Fever & 120 & 85.7 \\
\hline & Body weakness & 96 & 68.6 \\
\hline & Constipation & 12 & 8.6 \\
\hline & Vomiting & 66 & 47.1 \\
\hline & Headache (HA) & 94 & 67.1 \\
\hline & Stomach disorder & 12 & 8.6 \\
\hline \multirow[t]{5}{*}{$\begin{array}{l}\text { Signs and } \\
\text { symptoms }\end{array}$} & $\begin{array}{l}\text { At least three of the } \\
\text { following: fever, body } \\
\text { weakness, vomiting, HA }\end{array}$ & 77 & 55 \\
\hline & Use of ITNs & 112 & 80 \\
\hline & Avoid dirty water & 10 & 7.1 \\
\hline & Clean environment & 110 & 78.6 \\
\hline & Safe sexual intercourse & 41 & 29.3 \\
\hline Prevention & ${ }_{\text {ITNS \& }}$ clean environment & 88 & 62.9 \\
\hline
\end{tabular}

${ }^{\dagger}$ Some respondents selected more than one answer. Number of responses exceeded 140-participant total. Bolded answers: Correct responses

${ }^{\ddagger}$ ITNs: Insecticide - treated bed nets 
Table 3

Demographic factors of participants with correct knowledge of malaria

\begin{tabular}{|c|c|c|c|c|}
\hline & \multirow[b]{2}{*}{ Demographics } & \multirow{2}{*}{$\begin{array}{l}\text { Correct Knowledge } \\
\text { [n(\%)] }\end{array}$} & \multicolumn{2}{|c|}{ Level of Significance } \\
\hline & & & Chi-Square & $\underline{\text { P-Value }}$ \\
\hline & Male & $68(71.6)$ & .47 & .83 \\
\hline \multirow[t]{4}{*}{ Gender } & Female & $33(73.3)$ & & \\
\hline & $<20$ & $4(66.7)$ & \multirow[t]{2}{*}{.79} & \multirow[t]{2}{*}{.84} \\
\hline & $20-29$ & $48(75)$ & & \\
\hline & $30-39$ & $40(71.4)$ & & \\
\hline \multirow[t]{3}{*}{ Age group } & $40-49$ & $9(64.3)$ & & \\
\hline & Pharmacist/MD/Pharmacy Assistant ${ }^{\dagger}$ & $8(100)$ & \multirow[t]{2}{*}{14.69} & \multirow[t]{2}{*}{$<.005$} \\
\hline & Nurse & $42(76.4)$ & & \\
\hline \multirow{2}{*}{$\begin{array}{l}\text { Professional } \\
\text { Qualification }\end{array}$} & Other Degrees & 14(63.6) & & \\
\hline & No Professional Diploma & $32(58.2)$ & & \\
\hline \multirow{3}{*}{$\begin{array}{c}\text { Dispensary } \\
\text { Type }\end{array}$} & Hospital/community Pharmacy ${ }^{\ddagger}$ & $47(79.7)$ & 2.87 & .09 \\
\hline & Drugstore & $54(66.7)$ & & \\
\hline & $<5$ & $47(54)$ & 11.19 & $<.005$ \\
\hline \multirow{2}{*}{$\begin{array}{l}\text { Experience } \\
\text { (years) }\end{array}$} & $5-10$ & $11(36.7)$ & & \\
\hline & $>10$ & $19(82.6)$ & & \\
\hline
\end{tabular}

${ }^{\dagger}$ Pharmacist Assistant: Individual that contributes to the overall medication dispensing process in the presence or absence of formalized educational training.

${ }^{\dagger} \mathrm{MD}:$ Medical Doctor

${ }^{\ddagger}$ Hospital Pharmacy: A pharmacy location that dispenses traditional medications within an inpatient setting.

${ }^{\ddagger}$ Community Pharmacy: A pharmacy location that dispenses traditional medications within a residential clinic facility.

${ }^{\ddagger}$ Drugstore: A medicinal market that encompasses sell of traditional and nontraditional medications and holistic remedies. 
Table 4

Conditions for antimalarial drug dispensing $(\mathrm{N}=139)^{\dagger}$

\begin{tabular}{|c|c|c|c|c|c|}
\hline \multirow{2}{*}{$\begin{array}{l}\text { Conditions for dispensing } \\
\text { antimalarials }\end{array}$} & \multirow{2}{*}{ Response } & \multicolumn{2}{|c|}{ Dispensing Type $n(\%)$} & \multicolumn{2}{|c|}{ Level of Significance } \\
\hline & & $\begin{array}{l}\text { Hospital/community } \\
\mathrm{N}=58\end{array}$ & $\begin{array}{l}\text { Drugstore } \\
\mathrm{N}=81\end{array}$ & Chi-square & P-value \\
\hline \multirow{2}{*}{$\begin{array}{l}\text { Prescription by } \\
\text { physician/pharmacist/nurse }\end{array}$} & Yes & $46(79.3)$ & $62(76.5)$ & & \\
\hline & No & $12(20.7)$ & 19(23.5) & 149 & .70 \\
\hline \multirow{2}{*}{$\begin{array}{l}\text { Prescription by any health } \\
\text { worker }\end{array}$} & Yes & $17(29.3)$ & $27(33.3)$ & & \\
\hline & No & $41(70.7)$ & $54(66.7)$ & .253 & .61 \\
\hline \multirow[t]{2}{*}{ Prescription by anybody ${ }^{\ddagger}$} & Yes & $1(1.7)$ & $9(11.1)$ & & \\
\hline & No & $57(98.3)$ & $72(88.9)$ & 4.461 & .06 \\
\hline \multirow{2}{*}{$\begin{array}{l}\text { Overall dispensing } \\
\text { practices }\end{array}$} & ${ }^{*} 1_{\text {Good }}$ & $30(51.7)$ & $26(32.1)$ & & \\
\hline & $*^{2}$ Poor & $28(48.3)$ & $55(67.9)$ & 5.411 & .02 \\
\hline
\end{tabular}

${ }^{\dagger}$ One hospital/community pharmacy respondent did not complete this portion of the survey (139/140)

${ }^{\ddagger}$ Anybody: Any individual, including but not limited to physician, pharmacist, nurse, or any other individual

$* 1$ If conditions for dispensing are exclusively from prescription by physician/nurse/pharmacist

$* 2$ Conditions for dispensing include prescription from any of the following: anybody, any health worker 